\title{
Development and Validation of QuEChERS Method for Estimation of Propamocarb Residues in Tomato (Lycopersicon esculentum Mill) and Soil
}

\author{
Sanjay Kumar Sahoo*, Raminderjit Singh Battu, Balwinder Singh \\ Pesticide Residue Analysis Laboratory, Department of Entomology, \\ Punjab Agricultural University, Ludhiana, India \\ E-mail: "sksahoo_2006@rediffmail.com \\ Received November 1, 2011; revised December 5, 2011; accepted December 16, 2011
}

\begin{abstract}
An easy, simple and efficient analytical method was standardized and validated for the estimation of residues of propamocarb in tomato and soil. QuEChERS method included extraction of the sample with ethyl acetate and cleanup by treatment with PSA and graphatised carbon. Final clear extracts of ethyl acetate were concentrated under vacuum to almost dryness and reconstituted into hexane. The residues of propamocarbwere estimated using gas chromatograph-mass spectrometry (GC-MS). Propamocarb presented a distinct peak at retention time of $8.962 \mathrm{~min}$. Consistent recoveries of propamocarb ranging from 87 to 92 percent were observed when samples were spiked at $0.10,0.50$ and $1.00 \mathrm{mg} \cdot \mathrm{kg}^{-1}$ levels. The limit of quantification (LOQ) of this method was determined to be $0.10 \mathrm{mg} \cdot \mathrm{kg}^{-1}$.
\end{abstract}

Keywords: QuEChERS, Propamocarb, Tomato, Soil, GC-MS

\section{Introduction}

Propamocarb hydrochloride [propyl 3-(dimethylamino) propylcarbamate hydrochoride] shown in Figure 1, a systemic fungicide with protective action against phycomycetous diseases (Pythium, Phytophthora spp.), is used on a wide variety of mainly greenhouse vegetables [1]. Propamocarb was introduced into European markets for control of oomycete pathogens in ornamental crops and certain vegetables [2]. It has been widely used as a soil drench against Phytophthora and Pythium diseases of numerous crops [3-6]. More successfully, it has been used to control potato late blight by Phytopthera infestans, where metalaxyl-resistant populations presented cause a serious problem $[7,8]$. Due to its lack of adverse effects on beneficial microorganisms such as mycorrhizae and Trichoderma species, propamocarb has been considered as a good component of IPM programs $[9,10]$.

Gas chromatographic determination of propamocarb in agricultural products have appeared in the literature [11] where the analyte was extracted with acetone-water and cleaned up by liquid-liquid partition into diethyl ether and analysed by GC. The object of this study has been the development of a QuEChERS technique for fast, ac- curate and direct determination of propamocarb in commercial pesticides. The method can be used in the quantitative analysis of the analyte in different agricultural products, also reducing as much as organic solvents fulfilling the purposes to establish a wider acceptability of the methodology.

\section{Material and Methods}

\subsection{Standards and Reagents}

The technical grade analytical standard of propamocarb

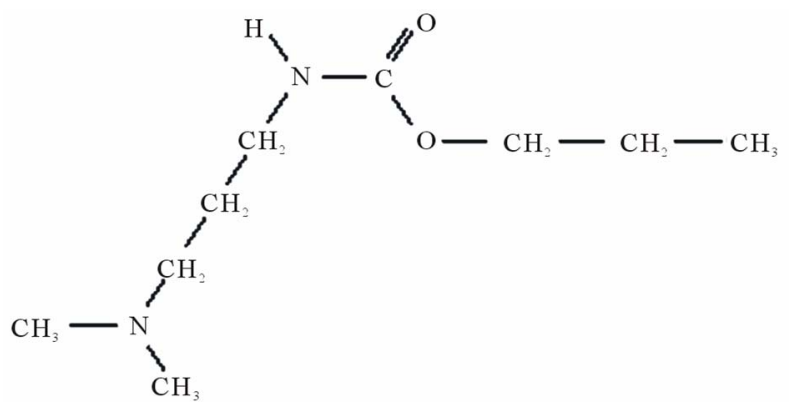

Figure 1. Structure of propamocarb. 
(purity $96.8 \%$ ) was supplied by $\mathrm{M} / \mathrm{s}$ Bayer CropScience India Ltd., Mumbai, India and stored at $-10^{\circ} \mathrm{C}$ in a deep freezer. Solvents like ethyl acetate and hexane were obtained from E. Merck (India) Limited, Mumbai. Sodium chloride was also obtained from E. Merck (India) Limited, Mumbai. Sodium sulfate anhydrous was from S. D. Fine Chemicals, Mumbai. Activated anhydrous $\mathrm{MgSO}_{4}$ was also obtained from E. Merck (India) Limited, Mumbai. Primary Secondary Amine (PSA) Sorbent and graphatised carbon decolorizing powder were obtained from Sigma-Aldrich, Mumbai, India. All common solvents were redistilled in all-glass apparatus before use. The suitability of the solvents and other chemicals were ensured by running reagent blanks before actual analysis.

\subsection{Apparatus}

Estimation of propamocarb residues were carried out on a GC (Shimadzu 2010) coupled with mass detector (Fisons MD-800, quadrupole mass detector) equipped with capillary column (Rtx-5 Sil MS, $30 \mathrm{~m} \times 0.25 \mathrm{~mm}$ i.d. $\times 0.25 \mu \mathrm{m}$ film thickness). Rotary vacuum film evaporator (Heidolph Labrota 4002) was supplied by Heidolph, Germany was used for concentration of sample. A high speed homogenizer (Heidolph Silent Crusher $-\mathrm{M}^{\circledR}$ ) was used for homogenization of sample.

\subsection{Standard Solution}

A standard stock solution of propamocarb $(1 \mathrm{mg} / \mathrm{mL})$ was prepared in hexane. The standard solutions required for preparing a calibration curve $(0.10,0.25,0.50,1.00$, 1.50 and $2.00 \mu \mathrm{g} / \mathrm{mL}$ ) were prepared from stock solution by serial dilutions with hexane. All standard solutions were stored at $-4^{\circ} \mathrm{C}$ before use.

\section{QuEChERS Sample Preparation}

The tomato and soil samples were prepared by following QuEChERS method for the determination of propamocarb residues shown in Figure 2.

\subsection{Tomato}

A sub sample of $15 \mathrm{~g}$ tomato was weighed into a $50 \mathrm{~mL}$ polypropylene tube and added $30 \mathrm{~mL}$ ethyl acetate. The sample was homogenized using high speed homogenizer (Heidolph Silent Crusher-M ${ }^{\circledR}$ ) for 2 - $3 \mathrm{~min}$ at 14 $15,000 \mathrm{rpm}$. Anhydrous sodium chloride $(\mathrm{NaCl}) 10 \pm 0.1$ $\mathrm{g}$ was added to homogenized sample for phase separation. The contents were centrifuged at $25-3,000 \mathrm{rpm}$ for 3 min. An aliquot of $15 \mathrm{~mL}$ ethyl acetate layer was transferred over $10 \pm 0.1 \mathrm{~g}$ sodium sulfate $\left(\mathrm{Na}_{2} \mathrm{SO}_{4}\right)$ in a test

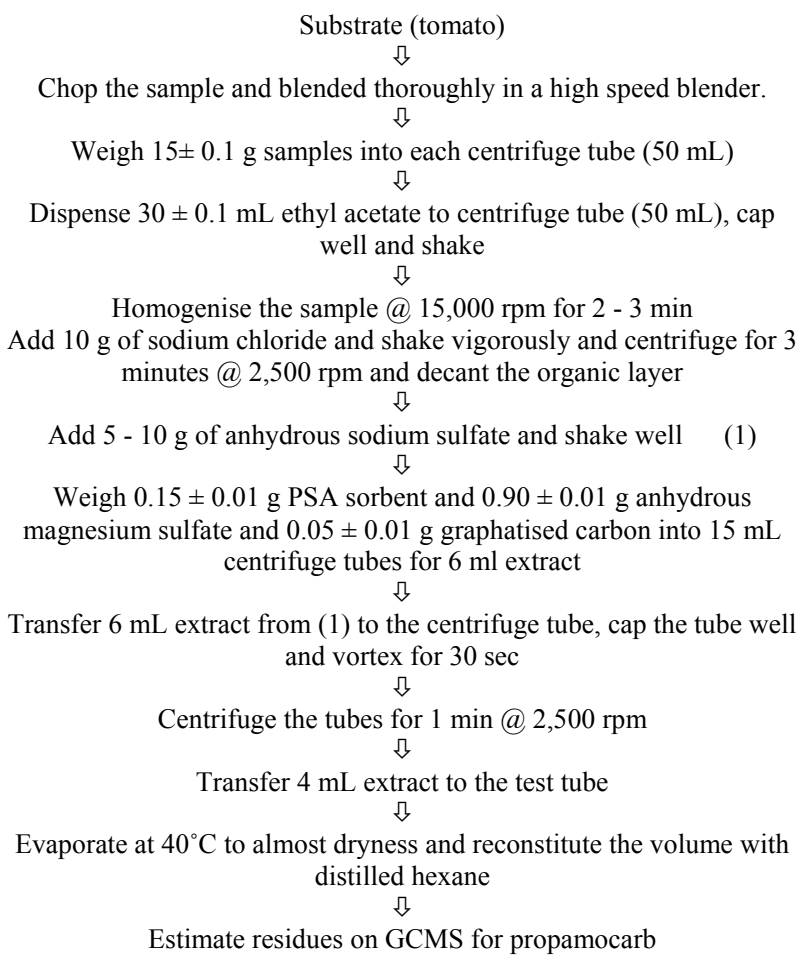

Figure 2. Flow chart of exteaction and cleanup methodology for propamocarb.

tube. The ethyl acetate extract subjected to cleanup by dispersive solid phase extraction (DSPE). An aliquot of 6 $\mathrm{ml}$ acetonitrile was taken in a test tube containing $0.15 \pm$ $0.01 \mathrm{~g}$ PSA sorbent, $0.90 \pm 0.01 \mathrm{~g}$ anhydrous $\mathrm{MgSO}_{4}$ and $0.05 \pm 0.01 \mathrm{~g}$ graphatised carbon and the content was thoroughly mixed on vortex shaker. Again centrifuged at $25-3,000 \mathrm{rpm}$ for $1 \mathrm{~min} .4 \mathrm{~mL}$ aliquot of this ethyl acetate extract was evaporated to dryness using low volume evaporator to dryness using low volume evaporator at $40^{\circ} \mathrm{C}$. Volume was made with distilled hexane.

\subsection{Soil}

A sub sample of $10 \mathrm{~g}$ soil was weighed into a $50 \mathrm{~mL}$ centrifuge tube and water was added before the initial extraction to get a total of $10 \mathrm{~mL}$ water and added $20 \mathrm{~mL}$ ethyl acetate. The sample was homogenized using high speed homogenizer (Heidolph Silent Crusher- $\mathrm{M}^{\circledR}$ ) for 2 $3 \mathrm{~min}$ at $14-15,000 \mathrm{rpm}$. Anhydrous sodium chloride $(\mathrm{NaCl}) 3 \pm 0.1 \mathrm{~g}$ was added to homogenized sample for phase separation. The contents were centrifuged at 25 $3000 \mathrm{rpm}$ for $3 \mathrm{~min}$. An aliquot of $15 \mathrm{~mL}$ ethyl acetate layer was transferred over $10 \pm 0.1 \mathrm{~g}$ sodium sulfate $\left(\mathrm{Na}_{2} \mathrm{SO}_{4}\right)$ in a test tube. The ethyl acetate extract subjected to cleanup by dispersive solid phase extraction (DSPE). An aliquot of $6 \mathrm{ml}$ acetonitrile was taken in a test tube containing $0.15 \pm 0.01 \mathrm{~g}$ PSA sorbent, $0.90 \pm$ 
$0.01 \mathrm{~g}$ anhydrous $\mathrm{MgSO}_{4}$ and $0.05 \pm 0.01 \mathrm{~g}$ and the content was thoroughly mixed on vortex shaker. Again centrifuged at $25-3000 \mathrm{rpm}$ for $1 \mathrm{~min} .4 \mathrm{~mL}$ aliquot of this ethyl acetate extract was evaporated to dryness using low volume evaporator to dryness using low volume evaporator at $40^{\circ} \mathrm{C}$. Volume was made with distilled hexane.

\section{Estimation of Propamocarb Residues}

The estimation of propamocarb residues was done by GC-MS. Helium was used as a carrier gas with flow rate of $1 \mathrm{ml}^{-1}$. The injector temperature was maintained at $260^{\circ} \mathrm{C}$, Interface and ion source temperatures were maintained at $220^{\circ} \mathrm{C}$ and $200^{\circ} \mathrm{C}$, respectively. Injection volume was $1 \mu \mathrm{l}$ in split less mode. Detector voltage was maintained at $0.9 \mathrm{KV}$ in SIM mode. The samples were injected and confirmed on electron ionization (EI) mode. The compounds were identified based on $\mathrm{m} / \mathrm{z}$ ratio of total ion chromatograph (TIC) and fragmentations of selective ions monitoring (SIM) compared with fragmentations of different mass numbers obtained with standard propamocarb. The compounds were identified both in total scan and SIM mode based on $\mathrm{m} / \mathrm{z}$ ratio. The sensitivity of the instrument increased in SIM mode as the most abundant fragment ions, characteristics of the analyte, were counted. The mass spectra of standard propamocarb showed the most abundant ions at $\mathrm{m} / \mathrm{z} 72,129$, 143, 188 and base peak at 58. These ions values were compared with the tomato and soil samples spiked with propamocarb and tomato samples collected from treated plots for quantitation and confirmation of propamocarb residues.

\section{Results and Discussions}

\subsection{GCMS Chromatograms of Propamocarb}

GCMS detection has proven to be a good for propamocarb determination because no derivation step is needed. Under the chosen conditions, propamocarb showed a retention time of $8.962 \mathrm{~min}$. The mass spectra of standard propamocarb showed the most abundant ions at $\mathrm{m} / \mathrm{z} 72,129,143,188$ and base peak at 58 shown in Figure 3.

\subsection{Validation of the Method}

As the quantitative determination of propamocarb in tomato and soil is directly related to the evaluation and interpretation of data, a reliable method is required which is reproducible and can be applicable to different commodities. The method was fully validated according to bio analytical method recommendations described in the
Food and Drug Administration (FDA) guidelines in terms of selectivity, linearity, precision (repeatability), precision (reproducibility), and accuracy for both detection systems $[12,13]$.

\subsection{Linearity}

For most chromatographic procedures a linear relation is observed between detector response $(y)$ and analyte concentration $(x)$. This can be expressed as a linear regression equation: $y=a+b x$. The parameters obtained by the selected chromatographic conditions for propamocarb correspond to: $y=27005 x+11414, R^{2}=0.999$ was shown in Figure 4. The linearity of a method is a measure of range within which the results are directly, or by a well defined mathematical transformation, proportional to the concentration of analyte in samples within a given range [14].

\subsection{Limit of Detection and Limit of Quantitation}

The limit of detection (LOD) is the lowest concentration of analyte detectable by an analytical method and is expressed in concentration units. The limit of quantification (LOQ) is the lowest solute concentration that can be determined with acceptable precision and accuracy, under the stated experimental conditions. It is also expressed in concentration units. The residues of propamocarb were estimated by comparison of peak height of standard and that of the unknown samples run under identical conditions. Fairly good response i.e. about $10 \%$ of full scale defection was observed by injecting $0.2 \mathrm{ng}$ of propamocarb. When tomato sample (15 g) was processed and 4 $\mathrm{mL}$ aliquot was concentrated to a final volume $2 \mathrm{~mL}$ from which $2 \mu \mathrm{L}$ was injected (equivalent to $2 \mathrm{mg}$ sample) into the instrument, there was no base line noise. In case of soil samples $(10 \mathrm{~g})$, was processed and $4 \mathrm{~mL}$ aliquot was concentrated to a final volume $2 \mathrm{~mL}$ from which $2 \mu \mathrm{L}$ was injected (equivalent to $2 \mathrm{mg}$ sample) into the instrument, there was no base line noise. Therefore, the limit of quantification (LOQ) was observed to be $0.1 \mathrm{mg} \cdot \mathrm{kg}^{-1}$ for both the substrates. The limit of detection (LOD) was determined as the concentration having peak area three times higher in relation to the noise of the base line at the retention time of the peak of interest. Therefore, the LOD was calculated to be $0.03 \mathrm{mg} \cdot \mathrm{kg}^{-1}$ for propamocarb.

\subsection{Precision}

\subsubsection{Precision (Repeatability)}

Precision (repeatability) reflects the variation in results when repetitive analyses are made on the same condi- 


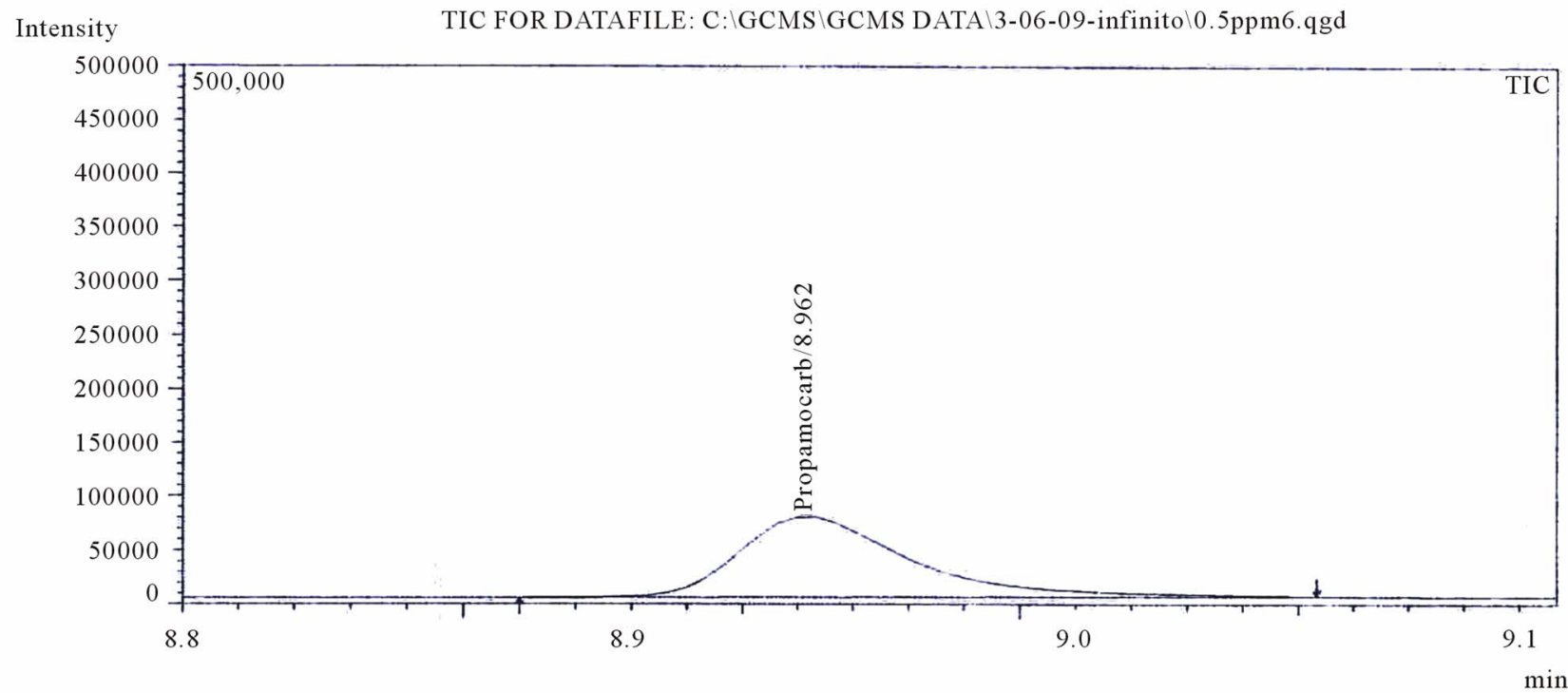

(a)

Intensity

TIC FOR DATAFILE: C: GGMS \GCMS DATA $\backslash 02-07-2010 \backslash 3-06-09-$ infinito $\backslash$ Tomato fortifed = 0.1ppm.qgd

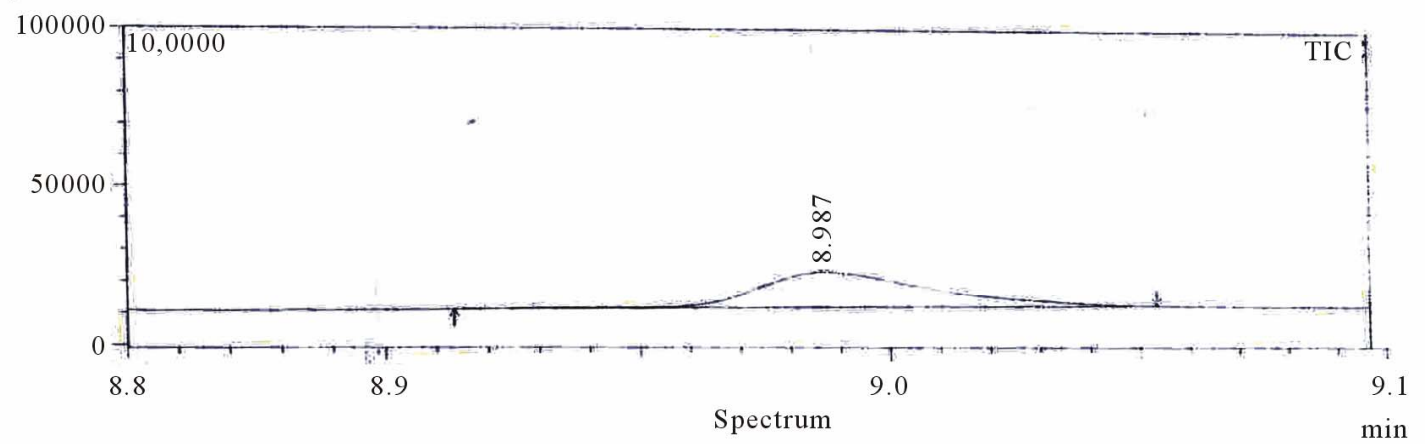

Line\#:1 r.tIME:9.0 (Scan\#:42)

MassPeaks: 5

RawMode:Averaged 9.0-9.0 (41-43) BasePeak:58(9661)

BG Mode:Cale from Peak Group 1- Event 1

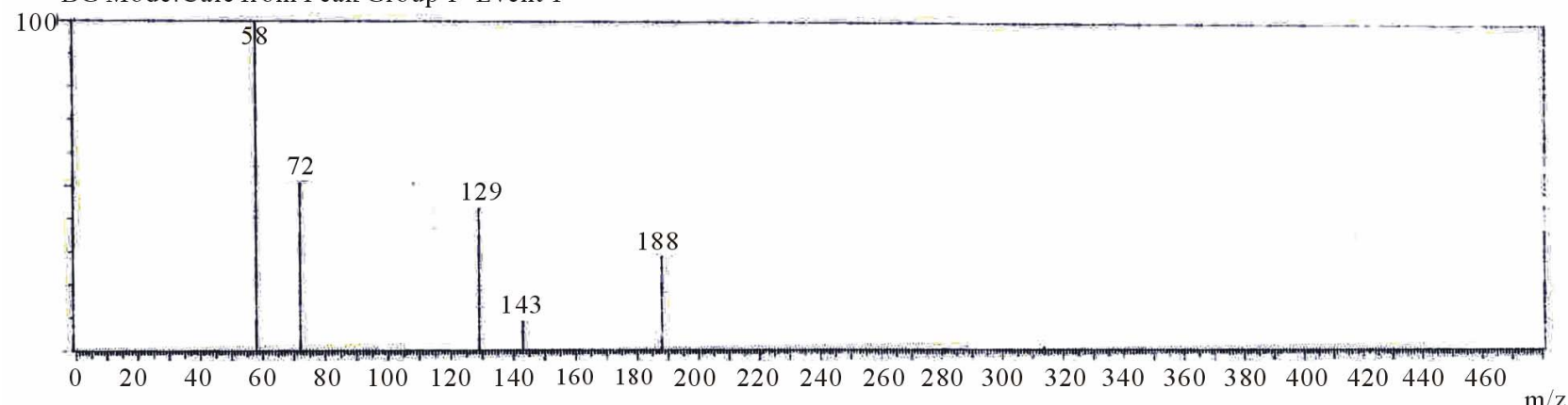

(b)

Figure 3. GC-MS chromatograms of (a) Standard propamocarb and (b) Fortified tomato sample and its mass ions.

tions. The numerical value used is the relative standard deviation for repeatability $\left(\mathrm{RSD}_{\mathrm{r}}\right)$. Repeatability of the developed analysis method was determined by adding propamocarb in different concentrations to blank sam- ples. The within-batch recovery and repeatability $\left(\mathrm{RSD}_{\mathrm{r}}\right)$ of spiked samples at the levels of 1.00, 0.50 and 0.10 $\mathrm{mg} \cdot \mathrm{kg}^{-1}$ for propamocarb are summarized in Table 1 . The precision (repeatability) in tomato range from $2.22 \%$ 


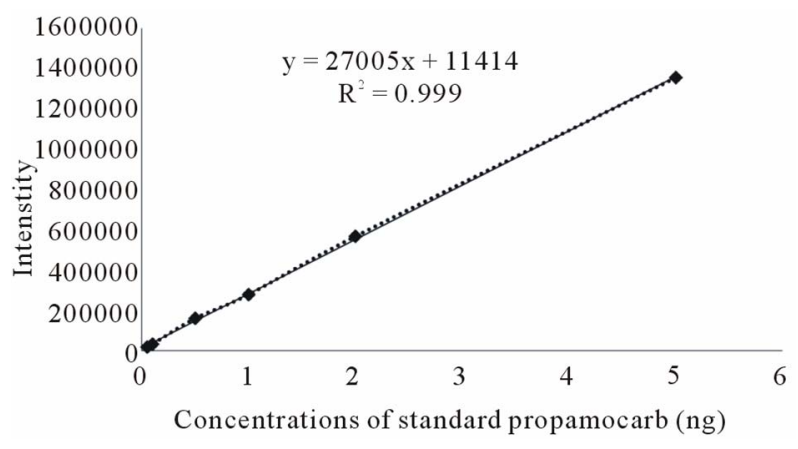

Figure 4. Calibration curve of different concentrations of propamocarb.

Table 1. Recovery of propamocarb in tomato and soil $(n=$ 6).

\begin{tabular}{ccccc}
\hline \multirow{2}{*}{ Substrates } & $\begin{array}{c}\text { Level of } \\
\text { fortification } \\
\left(\mathrm{mg} \cdot \mathrm{kg}^{-1}\right)\end{array}$ & \multicolumn{3}{c}{ Propamocarb } \\
\cline { 3 - 5 } & 1.00 & 91.67 & 4.16 & 4.54 \\
\multirow{2}{*}{ Tomato } & 0.50 & 90.00 & 2.00 & 2.22 \\
& 0.10 & 87.33 & 2.52 & 2.89 \\
& 1.00 & 92.35 & 2.57 & 2.78 \\
& 0.50 & 86.67 & 2.08 & 2.40 \\
& 0.10 & 86.67 & 1.15 & 1.33 \\
\hline
\end{tabular}

${ }^{\mathrm{a}} \mathrm{SD}=$ Standard deviation; ${ }^{\mathrm{b}} \mathrm{RSD}_{\mathrm{r}}=$ Relative standard deviation for repeatability.

to $4.54 \%$ for propamocarb, in soil ranging from $1.3 \%$ to $2.78 \%$ for propamocarb. The results are fairly good for the concentration levels investigated.

\subsubsection{Precision (Reproducibility)}

Precision (reproducibility) is the degree of agreement obtained by the analysis of the same sample under various test conditions. The usually numerical value used is the relative standard deviation for reproducibility $\left(\mathrm{RSD}_{\mathrm{R}}\right)$. The reproducibility of this analytical method was determined by analyzing spiked samples under various test conditions (different analysts, different instruments and different days). The between-batch recoveries and reproducibility $\left(\mathrm{RSD}_{\mathrm{R}}\right)$ investigated at several levels are given in Table 2. The $\mathrm{RSD}_{\mathrm{R}}$ values for propamocarb residues in tomato and soil were very good and well within $15 \%$ at all concentrations.

\subsection{Accuracy}

The accuracy of an analytical method is the agreement between the true value of analyte in the sample and the value obtained by analysis. Accuracy is usually ex-
Table 2. Recovery and RSD values obtained from analyses of samples spiked with propamocarb.

\begin{tabular}{ccccc}
\hline \multirow{2}{*}{ Sample } & Day & \multicolumn{3}{c}{ Propamocarb } \\
\cline { 3 - 5 } & & Recovery \% & ${ }^{\mathrm{a}} \mathrm{RSD}_{\mathrm{r}} \%$ & ${ }^{\mathrm{b}} \mathrm{RSD}_{\mathrm{R}} \%$ \\
\hline \multirow{2}{*}{ Tomato } & 2 & 91.04 & 3.11 & 7.88 \\
& 3 & 86.29 & 2.65 & \\
& 1 & 86.67 & 1.33 & \\
Soil & 2 & 88.72 & 3.64 & 9.87 \\
& 3 & 93.12 & 2.37 & \\
\hline
\end{tabular}

${ }^{a} \mathrm{RSD}_{\mathrm{r}}=$ Relative standard deviation for repeatability; ${ }^{\mathrm{b}} \mathrm{RSD}_{\mathrm{R}}=$ Relative standard deviation for reproducibility.

pressed as the recovery by the assay of known, added amounts of analyte [14]. The recovery tests were carried out on three replicates at each spike level. Results are the average from three injections. The average recoveries obtained for propamocarb at all concentrations and conditions investigated (Tables $\mathbf{1}$ and $\mathbf{2}$ ) were determined as $87.85 \%$ and $87.52 \%$ in tomato and soil, respectively, for propamocarb, which are very satisfactory.

\section{Application of the Method to Real Samples}

Initially, the representative samples of tomato and soil were extracted in acetonitrile, but the recoveries were observed to be very poor. A representative $15 \mathrm{~g}$ sample of tomato was spiked with propamocarb at $0.10,0.50$ and $1.00 \mathrm{mg} \cdot \mathrm{kg}^{-1}$ level, extracted with ethyl acetate. The results were astonishing as the percent recoveries ranged from 86.67 to 92.35 . The same method was applied to tomato and soil the results were found to be excellent. The percent recoveries of propamocarb from different vegetable substrates spiked at $0.10,0.50$ and $1.00 \mathrm{mg} \cdot \mathrm{kg}^{-1}$ are reported in Table 1. Each value is the mean \pm standard deviation of six replicate determinations. The results were encouraging and suggested that the method could be extended to more substrates. Moreover, it is simple, efficient, and easy to adopt in laboratories engaged in pesticide residue analysis.

\section{Conclusions}

We used a highly sensitive, easy, less time consuming and cost effective method for quantifying pesticide residues in tomato and soil samples. However, as the extraction was done with ethyl acetate, the method can be suitable apply for quantifying propamocarb in other ag- 
ricultural products and also for other pesticides simultaneously as incase propamocarb is an active component in the formulation mixtures of Infinto.

\section{References}

[1] C. D. S. Tomlin, "The Pesticide Manual," 12th Edition, British Crop Protection Council, Bracknel, 2000, pp. 769.

[2] E. A. Pieroh, W. Krass and C. Hemmen, "Propamocarb, ein Neues Fungizid zur Abwehr von Oomyceten im Zierpflaanzen-und Gemusebau," Meded Fac Landbouw Rijksuniv Gent, Vol. 43, 1978, pp. 933-942.

[3] Y. Cohen and M. D. Coffey, "Systemic Fungicides and Control of Oomycetes," Annual Review of Phytopathology, Vol. 24, No. 1, 1986, pp. 311-318. doi:10.1146/annurev.py.24.090186.001523

[4] L. Englander, J. A. Merlino and J. J. McGuire, “ Efficacy of Two New Systemic Fungicides and Ethazole for Control of Phytophthora Root Rot of Rhododendron, and Spread of Phytophthora cinnamomi in Propagation Benches," Phytopathology, Vol. 70, 1986, pp. 1175-1179. doi:10.1094/Phyto-70-1175

[5] L. Rapp and J. Richter, "Effect of Propamocarb-Hydrochloride (Previcur N) on Several Isolates of SOME Pythium and Phytophthora Species in Vitro and in Vivo," Journal for Plant Diseases and Plant Protection, Vol. 43, 1982, pp. 933-942.

[6] J. J. Reilly, "Chemical Control of Black Shank of Tobacco," Plant Disease, Vol. 64, 1980, pp. 274-277. doi:10.1094/PD-64-274

[7] R. A. Bardsley, R. C. Shattock and J. P. Day, "Studies Investigating the Sensitivity of Phytophthora infestans to Propamocarb Hydrochloride," Brighton Crop Protection Conference-Pests and Diseases, Alton, UK, 1996, pp. 719-724.
[8] R. A. Bardsley, R. C. Shattock and J. P. Day, "Studies Comparing the Sensitivity of European and USA Isolates of Phytophthora infestans to Propamocarb Hydrochloride," Brighton Crop Protection Conference-Pests and Diseases, Alton, UK, 1998, pp. 523-528.

[9] L. L. May and H. Kimati, "Controle de Phytophthora parasitica com Fungicide e Efeito Desses Produtos no Crescimento Micelial de Trichoderma," Summa Phytopathologica, Vol. 26, 2000, pp. 52-57.

[10] T. H. Wilde, "Propamocarb-HCl, a Fungicide Suitable for Integrated Pest Management. Tomato and Pepper Production in the Tropics," Proceedings of International Symposium Integrated Management Practices, Taiwan, 1990, pp. 306.

[11] T. Nagayama, M. Kobayashi, H. Shioda and T. Tomomatsu, "Gas Chromatographic Determination of Propamocarb in Agricultural Commodities," Journal of AOAC International, Vol. 9, No. 3, 1997, pp. 769-772.

[12] Food and Drug Administration, "Guidance for Industry Bioanalytical Method Validation,” 2001. http://www.fda.gov/downloads/Drugs/GuidanceComplian ceRegulatoryInformation/Guidances/UCM070107.pdf

[13] C. T. Viswanathan, S. Bansal, B. Booth, A. J. DeStefano, M. J. Rose, J. Sailstad, V. P. Shah, J. P. Skelly, P. G. Swann and R. Weiner, "Quantitative Bioanalytical Methods Validation and Implementation: Best Practices for Chromatographic and Ligand Binding Assays," Pharmaceutical Research, Vol. 24, No. 10, 2007, pp. 1962-1973. doi:10.1007/s11095-007-9291-7

[14] E. Francotte, A. Davatz and P. Richert, "Development and Validation of Chiral High-Performance Liquid Chromatographic Methods for the Quantification of Valsartan and of the Tosylate of Valinebenzyl Ester," Journal of Chromatography B, Vol. 686, No. 1, 1996, pp. 77-83. doi:10.1016/S0378-4347(96)00242-3 